\title{
7 Gender and Race in the Digital Town Hall: Identity- Based Attacks Against US Legislators on Twitter
}

\author{
Sarah Sobieraj and Shaan Merchant
}

\subsection{Introduction}

In August 2018, amidst an unprecedented number of women running for public office in the US, the New York Times released a video of current and former female candidates talking about their experiences with harassment and sexism, much via social media, during their campaigns (Kerr, Tiefenthäler, \& Fineman, 2018). Throughout the video, the women describe abuse that is gendered and racialized. Among the women in the video is Iowa Democrat Kim Weaver, who pulled out of her 2016 congressional race amid a torrent of sexist and anti-Semitic abuse (Astor, 2018). There is ample reason to believe racist and sexist abuse plague white women and people of color once they hold office as well. In 2017, Senator Kirsten Gillibrand received a throng of sexist tweets after she called for Senator Al Franken's resignation. And as recently as June 2018, after Representative Maxine Waters called for lay people to confront Trump administration representatives in public, she faced such intimidation on- and offline that she cancelled two speaking engagements out of concern for her safety. This is not unique to politicians in the US. In 2016, British Member of Parliament Jess Phillips received 600 rape threats on Twitter in one day in response to strongly worded remarks she made about sexism from the left (Elliot \& Turner, 2017).

Previous research has identified abuse of politicians on social media but has not identified - and in some cases not looked for - racial or gender differences. The anecdotal evidence above, coupled with recent research documenting widespread digital harassment of people of color and white women in arenas ranging from gaming (Gray, 2012; Fox \& Tend, 2017) and academia (Ferber, 2018; Veletsianos et al., 2018) to journalism (Gardiner, 2018; Adams, 2018; Chen et al., 2018), suggests systematic research is needed to explore how participation in digital publics differs for political figures from historically underrepresented demographic groups. This research mines the content of tweets containing @mentions to 16 US legislators, revealing that male and female politicians on social media navigate very different digital worlds. What's more, we find particularly egregious hostility directed at female legislators of color, much of it explicitly identity-based, drawing on racist and sexist stereotypes and epithets to discredit, intimidate and shame the recipients.

These unevenly distributed consequences of public service represent tangible evidence of patterned resistance to political voice and visibility of those from historically underrepresented groups. This abuse undoubtedly has a variety of personal and political costs for the legislators targeted for attack, but we must also 
consider the social costs: as a result of this blowback, we lose qualified candidates and hear a narrower range of perspectives. The macro and micro implications of this hostile work environment will need to be explored more fully, as leaving Twitter, YouTube, and Facebook are not practical options in a political context where the populace increasingly gets information via social media platforms and evidence mounts that a robust social media presence helps candidates win elections.

\subsection{Literature}

There is a burgeoning body of literature that explores politicians' use of social media, particularly its role in campaigning (e.g. Bimber, 2014; Evans et al., 2014; Jungherr, 2015; Sweetser \& Lariscy, 2008) and constituent interaction (e.g. Jackson \& Lilleker, 2011; Larsson \& Øyvind, 2013; Waisbrod \& Amado, 2017). Research shows that most political leaders prefer to use these platforms to broadcast, showing greater interest in one-way communication than in engaging voters or constituents (Gibson et al., 2014; Graham et al., 2013; Hoffmann \& Suphan, 2016; Lev-On, 2011; Sweetser \& Lariscy, 2008). This is not particularly surprising given that members of the general public often respond to politicians in hostile, even abusive, ways. Most politicians in the US have experience with combative town hall meetings, uncomfortable encounters while canvassing, and being on the receiving end of rancorous phone calls. Lambasting and jeering politicians is not a new phenomenon - there is a long tradition of lashing out at politicians, with tactics ranging from heckling and hate mail to shoe and tomato throwing (Bennett, 1979; Ibrahim, 2009; Temkin \& Yanay, 1988).

While social media were not required to give politicians a hard time, platforms such as Twitter, Facebook, YouTube, and Instagram create new points of access for the public and offer opportunities for feedback that require little time, skill or expense. These new pathways for communication between political leaders and the public create new venues for negative and potentially embarrassing or harmful flak (in addition to more constructive engagement), while reducing the personal investment and the risk of repercussions for critics, particularly for those hiding behind the veil of anonymity.

Recent research documents harassment of political figures extending into the social media space (James et al., 2016; McLoughlin \& Ward, 2017). Yet, looking at the findings, one might conclude that the digital abuse is evenly distributed, something that seems empirically unlikely given existing identity-based hierarchies. James, Farnham, Sukhwal, Jones, Carlisle, and Henley (2016) conducted a four-site, crossnational survey of MP experiences with digital harassment in the UK, Australia, New Zealand and Norway and found a tremendous amount of abuse, but did not examine gender or racial patterns in their data. And, in 2017, McLoughlin and Ward conducted an analysis of tweets to MPs and found that the gender of the MPs didn't matter (they did not examine race). The most extensive academic work on harassment of political 
figures (online and offline) comes from the threat assessment literature, which focuses on the perpetrators and evaluates risk in nearly universal psychological terms without attending to the broader patterns of victimization (Dietz et al., 1991; Adams et al., 2006; Hoffman \& Sheridan, 2008; Meloy, 2014).

We have little research about how the digital aspects of public life vary for political leaders with different social locations, save an Amnesty International finding that among women, black, Asian, and minority ethnic MPs received $41 \%$ of the abusive tweets, even though white female MPs outnumber them nearly 8 to 1 (Stambolieva, 2017). This gap in our understanding exists even though there are reasons to suggest representatives of color and white women find digital publics more hostile than their white male counterparts. For example, evidence suggests that women in politics experience disproportionate amounts of violence offline (Dalton, 2017; Krook, 2017). Recently, Krook (2017) looked at journalistic accounts and research reports from nongovernmental organizations such as the National Democratic Institute and concluded that violence against women in politics is rampant, particularly in African countries. And as the first African American President, Barack Obama entered office faced with an unprecedented number of death threats (Parks and Heard, 2009). It seems counterintuitive that digital spaces would diverge from these offline patterns.

The fact that differential digital abuse of political leaders has not been studied is also peculiar, given the noteworthy gendered and racialized patterns to digital abuse in other arenas (Chen et al, 2018; Gardiner, 2018; Ferber, 2018; Nakamura, 2002; Daniels, 2009; Herring, 1999; Citron, 2014; Gray, 2012; Veletsianos et al., 2018; Sian, 2018). Watching politics - at least in the US - certainly suggests that gender and race matter. Consider the backlash against Florida Representative Frederica Wilson; After Wilson criticized President Donald Trump's phone call with Myeshia Johnson, the widow of La David T. Johnson who had been killed in Niger, she received a deluge of abuse via social media, much of which took on overtly racial and gendered dimensions. Figures 7.1-7.5 offer illustrations. The comments are pointedly racialized in several ways, including the disturbing suggestion that Wilson be lynched and the reference to her and Representative Maxine Waters as "race hustler pimps.” The references to Waters' physical attractiveness and the description of her as a "hooker" show the way that the pushback can be gendered. These examples also offer insight into the ways abuse can be intersectional, as seen in the reference to welfare - an implicit connection to one of the most pernicious stereotypes of black women in the US: the lazy, entitled welfare queen. Such vitriol is an example of what Moya Bailey calls "misogynoir," hatred directed towards black women where race and gender intersect and play a pivotal role in the discrimination, abuse and bias. ${ }^{27}$ US Representatives Ilhan Omar (D-MN) and Alexandria Ocasio-Cortez (D-NY) have also endured venomous identity-based abuse online. For example, the comments directed at Omar, a Somali-American and

27 See Bailey (2018) for a discussion of the origin of the term. 
observant Muslim, include references to her as a "rag head cunt," a "gorilla looking bitch," and a "sand nigger," as well as outlandish accusations of her participating in cannibalism, an incestuous relationship with her brother and terrorist activity (Sobieraj, 2019).

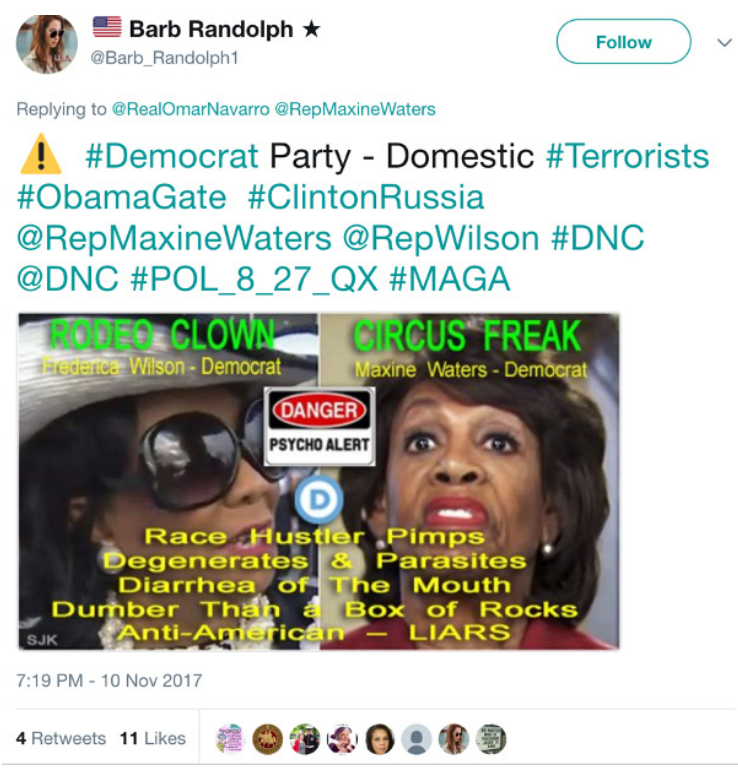

Figure 7.1: Tweet 1.

James Woods

@RealJamesWoods

Follow

When \#Democrats start wheeling out clowns

dressed as saloon hookers, they are trying desperately to swerve away from the news. \#UraniumOne

$10: 22$ AM -20 Oct 2017

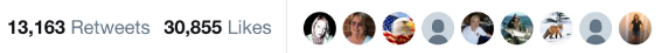

Q $1.7 \mathrm{~K} \quad \uparrow \downarrow 13 \mathrm{~K} \quad \bigcirc 31 \mathrm{~K}$

Figure 7.2: Tweet 2. 


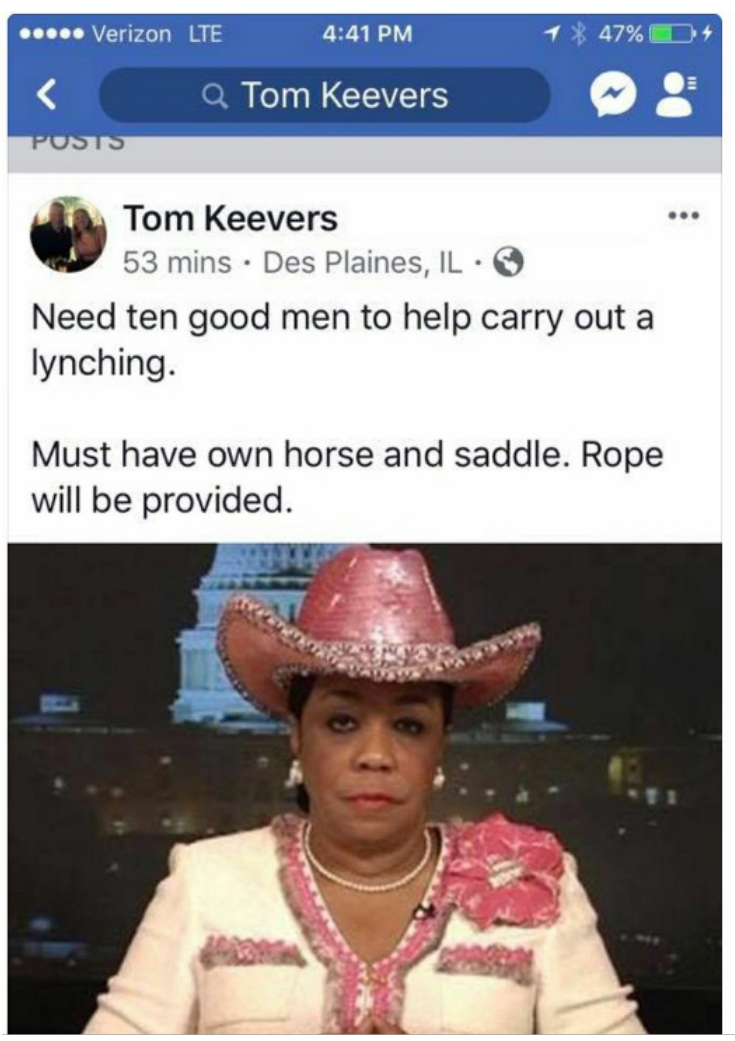

Figure 7.3: Tweet 3.

PatriotForever

@1PatriotForever

@RepWilson I hope that when I wake up every day, the 1st thing I'Il hear is that $U$ have finally been eliminated by 1 of UR own Welfare recipient constituents. Hallelujah I can't wait \& I hope $U$ don't use that as an excuse 2 resign, that someone close to you has a ht out on them

11:54 PM - 4 Nov 2017

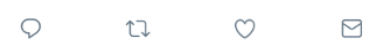

Figure 7.4: Tweet 4. 
Baglady @fubaglady · Oct 26

\#FreakyFreddy without makeup.

YIKES

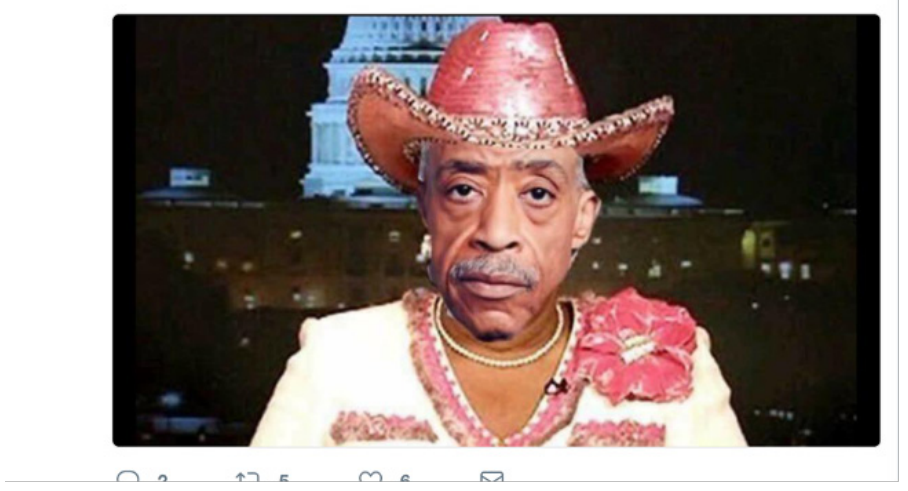

Figure 7.5: Tweet 5 .

Sobieraj $(2017,2020)$ highlights the ways in which such abuse is often heightened in male-dominated spheres such as science and technology, gaming and sports. It makes little sense intuitively that politics - another male-dominated space - would be different.

In light of this, McLoughlin and Ward's (2017) finding that gender is not a significant predictor in the abuse of MPs on Twitter seems suspect. We suspect the finding reflects a validity issue, generated as an artifact of the combination of the sentiment analysis and key-word coding process, which - while excellent at capturing obscenity and epithets -misses a great deal of hostile content. As a result, we revisit Twitter to explore how the experiences of legislators differ based on their racial and gender identities, but with a more interpretive approach and coding attuned to context.

\subsection{Methods}

To assess gender and racial differences in the treatment of politicians on Twitter, we examine tweets directed at legislators that incorporate three modes of harassment identified in Sobieraj (2017): attempts to discredit, intimidate, or shame. These kinds of abuse are more complicated to assess than the presence of particular words, but this reliability challenge is far outweighed by an enhanced ability to capture digital hostility in a meaningful way. We bolstered reliability through pre-testing and revision of the codebook, which resulted in lengthy operational definitions and examples to increase coder confidence and accuracy. In addition to checking for the presence of these modes of abuse, coders also assessed tweets for specific content, such as: the 
invocation of the legislators' race and gender and references to physical appearance, sex and the body, as Sobieraj (2017) identifies these as common in digital attacks against women, particularly women of color. Thumbnail descriptions of the variables are provided in Appendix A and the complete codebook is available upon request. We use these data to test the following hypotheses:

H1a: Attempts to discredit will be more common in tweets targeting female legislators than in those targeting men.

H1b: Attempts to discredit will be more common in tweets targeting legislators of color than in those targeting white legislators.

H1c: Attempts to discredit will be more common in tweets targeting female legislators of color than in those targeting other groups.

H2a: Attempts to intimidate will be more common in tweets targeting female legislators than in those targeting men.

H2b: Attempts to intimidate will be more common in tweets targeting legislators of color than in those targeting white legislators.

H2c: Attempts to intimidate will be more common in tweets targeting female legislators of color than in those targeting other groups.

H3a: Attempts to shame will be more common in tweets targeting female legislators than in those targeting men.

H3b: Attempts to shame will be more common in tweets targeting legislators of color than in those targeting white legislators.

H3c: Attempts to shame will be more common in tweets targeting female legislators of color than in those targeting other groups.

In terms of tweet content, we hypothesize:

H4a: The race (of the legislator) will be invoked more in tweets directed toward legislators of color than in those directed toward white legislators.

H4b: The race (of the legislator) will be invoked more in tweets directed toward female legislators of color than in those directed toward men of color.

H5a: The gender (of the legislator) will be invoked more in tweets directed toward female legislators than in those directed toward male legislators.

H5b: The gender (of the legislator) will be invoked more in tweets directed toward female legislators of color than in those directed toward white women. 
H6a: References to physical appearance, sexual situations and the body will be more common in tweets directed toward female legislators than in those directed toward male legislators.

H6b: References to physical appearance, sexual situations and the body will be more common in tweets directed toward female legislators of color than in those directed toward white women.

To isolate the effects of race and gender, we compiled a list of 16 US senators and representatives: four are white male politicians, four are white female politicians, four are male politicians of color and four are female politicians of color. Lack of diversity in the House and Senate prevented us from exploring more fine-grained racial distinctions or from taking sexual orientation and gender identity into account. Legislators were sampled purposively based on race, gender, visibility on Twitter, national name recognition and party. A nearly equal number of Democrats and Republicans are represented across groups; however, due to the low number of Republican women of color in congress, we were unable to achieve parity in that group (three Democrats (D) and one Republican (R) were selected). The 16 legislators included are: Leader Mitch McConnell (R), Speaker Paul Ryan (R), Sen. Bernie Sanders (D), Sen. Chuck Schumer (D), Sen. Cory Booker (D), Rep. Keith Ellison (D), Sen. Marco Rubio (R), Sen. Tim Scott (R), Sen. Susan Collins (R), Sen. Lisa Murkowski (R), Rep. Nancy Pelosi (D), Sen. Elizabeth Warren (D), Sen. Tammy Duckworth (D), Sen. Kamala Harris (D), Rep. Mia Love (R), Rep. Maxine Waters (D).

We amassed a database of tweets directed toward these 16 legislators via @ mentions (in the form of @replies and original tweets) using Twitter Archiver. We then conducted a census of the first 152 tweets directed at each legislator beginning at a specified time on March 6, 2018. For higher profile legislators, these 152 tweets were accrued in a matter of hours, while for others they spanned several days. When two or more politicians from our list were @mentioned in the same tweet, the tweet was discarded, unless the named politicians shared the same race and gender. In addition, a number of tweets were discarded because they had been deleted by the time of coding (in late March 2018), their links or images no longer existed, or they were identified as spam. Of the 2,432 possible tweets, 2,216 usable tweets were coded. Legislators averaged 138.5 usable tweets. The census $(n=2,216)$ consisted of 548 tweets @mentioning women of color, 566 @mentioning white women, 560 @ mentioning men of color, and $542 @$ @mentioning white men. After training and pilot testing, a team of three researchers manually coded the tweets. Two of the coders identify as non-Hispanic white women, and the third coder identifies as an AsianAmerican man. Inter-rater reliability testing indicates the level of agreement among coders to be very good, with Cohen's Kappa $=0.925$ ( $\mathrm{SE}=0.021$, with $95 \%$ confidence interval: from 0.883 to 0.967 ). 


\subsection{Analysis}

As described above, this research involves a census of each of the first 152 @mentions positioned toward each of the 16 legislators at the time of our investigation, eliminating the variation that would have been introduced had we relied on random selection to generate our sample. Because the study is based on a population, inference is not needed to interpret the findings, and can, in fact, be misleading (Gibbs et al., 2017; Gorard, 2013). We, therefore, follow Kenski, Filer, and Conway-Silver's 2018 analysis of campaign tweets and restrict our analysis to descriptive statistics.

\subsection{Findings}

Our first set of hypotheses looked at three common strategies used to limit the speakers' impact in digital publics as identified by Sobieraj (2017): discrediting, intimidating and shaming. Tweets that were coded as discrediting attempts include insinuations or accusations that the targeted legislator is not qualified, capable, well-informed, trustworthy or deserving of respect, as seen in this tweet: “@RepMaxineWaters Ms. Waters you should get ready for the asylum. You are disoriented, angry, and paranoid," which contains the not-so-subtle subtext that Waters should not be taken seriously because she is mentally unstable and overly-emotional. We hypothesized that these types of comments would be more common in tweets directed at female legislators (regardless of race) than male legislators, more common in tweets directed toward legislators of color (regardless of gender) than in those directed toward white legislators and most common in tweets directed at female legislators of color.

In terms of gender, our hypothesis was confirmed: $58.44 \%$ of tweets directed toward female legislators attempted to discredit them, while "only" $37.84 \%$ of tweets directed toward male legislators did so (see Table 7.1 and Figure 7.6). Tweets containing discrediting efforts are 2.31 times more likely to be directed at female legislators (odds ratio: $2.3097,95 \%$ CI: 1.9479 to $2.7386, \mathrm{p}<0.0001$ ). In contrast, legislators of color (48.65\%) and white legislators (47.74\%) received a roughly equivalent amount of such criticism (odds ratio: $0.9645,95 \%$ CI: 0.8164 to $1.1394, p=0.6707$ ). Figure six shows the percentage of tweets directed at each subgroup of legislators that contained discrediting attempts. The result prevents us from confirming hypothesis 1c; the highest percentage of discrediting tweets were directed at white women $(68.37 \%)$ rather than women of color $(57.12 \%)$ as we predicted. Attempts to discredit Nancy Pelosi were particularly common; a remarkable $82.7 \%$ of all tweets she received attempted to discredit her. 


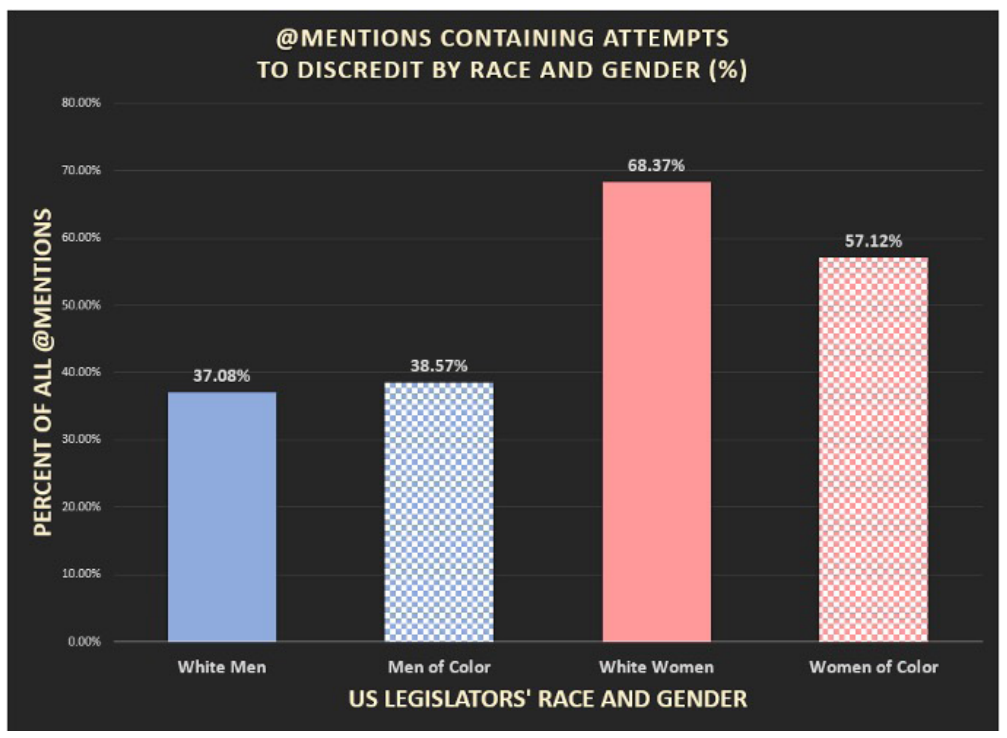

Figure 7.6: @mentions containing attempts to discredit.

Table 7.1: @mentions containing attempts to discredit.

\begin{tabular}{lllll}
\hline Legislators Mentioned & \#DISCREDIT & \#NONE & Total & \%DISCREDIT \\
\hline Women of Color & 313 & 235 & 548 & $\mathbf{5 7 . 1 2 \%}$ \\
White Women & 387 & 179 & 566 & $\mathbf{6 8 . 3 7 \%}$ \\
Men of Color & 216 & 344 & 560 & $\mathbf{3 8 . 5 7 \%}$ \\
White Men & 201 & 341 & 542 & $\mathbf{3 7 . 0 8 \%}$ \\
Total & 1,117 & 1,099 & 2,216 & \\
Women & 651 & 463 & 1,114 & $\mathbf{5 8 . 4 4 \%}$ \\
Men & 417 & 685 & 1,102 & $\mathbf{3 7 . 8 4 \%}$ \\
Total & 1,068 & 1,148 & 2,216 & \\
People of Color & 529 & 579 & 1,108 & $\mathbf{4 8 . 6 5 \%}$ \\
White People & 539 & 569 & 1,108 & $\mathbf{4 7 . 7 4 \%}$ \\
Total & 1,068 & 1,148 & 2,216 & \\
\hline
\end{tabular}

Tweets @mentioning legislators that contain direct or indirect threats of reputational, political or physical harm to the elected official, those close to them or their party are relatively infrequent (see Figure 7.7 and Table 7.2 ), ${ }^{28}$ but the intimidation attempts that

28 Importantly, while attempts to intimidate are not abundant, they are more common than this 
do appear are three and a half times as likely to be directed at female legislators than male legislators (odds ratio: 3.5258, 95\% CI: 1.5998 to 7.7704, $\mathrm{p}=0.0018$ ). However, while the percent of intimidating tweets positioned at legislators of color is higher $(1.81 \%)$ than those of white legislators $(1.44 \%)$, this difference is not statistically significant (odds ratio: $1.2546,95 \%$ CI: 0.6467 to $2.4341, \mathrm{p}=0.5024$ ). Stepping back to look at all four subgroups (Figure 7.7), we see intersectional effects at play. As hypothesized, attempts to intimidate are more common in tweets targeting female legislators of color than in those targeting other groups. Among legislators of color: female legislators of color received a higher proportion of intimidating tweets $(2.92 \%)$ than their male counterparts $(0.71 \%)$. Women of color also received a higher proportion of @mentions using intimidation tactics than white women, but the difference is smaller: $2.92 \%$ in contrast to $2.12 \%$.

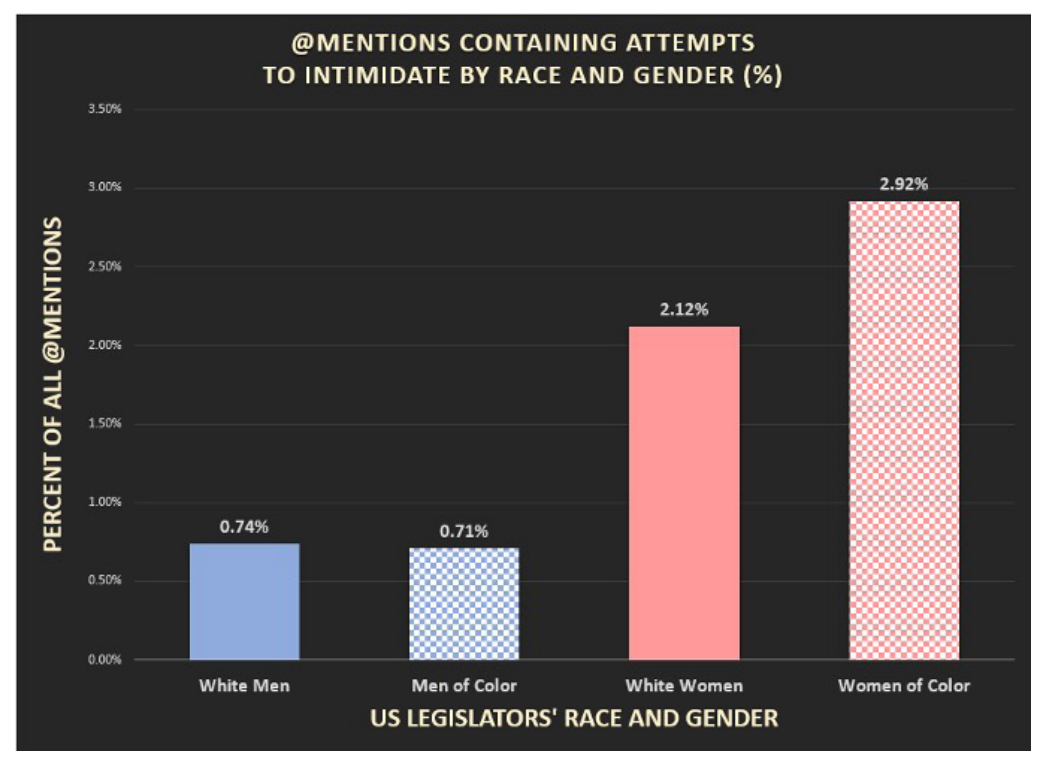

Figure 7.7: @mentions containing attempts to intimidate.

\footnotetext{
dataset suggests, as most overtly threatening tweets directed at public figures are caught relatively quickly by Twitter. Indeed, there were a number of tweets no longer available for coding and accounts that has been suspended at the time of coding. While these tweets may be missing for a variety of reasons, in all likelihood a subset contained content that would qualify as intimidation.
} 
Table 7.2: @mentions containing attempts to intimidate.

\begin{tabular}{lllll}
\hline Legislators & \#INTIMIDATE & \#NONE & Total & \% INTIMIDATE \\
\hline Women of Color & 16 & 532 & 548 & $\mathbf{5 7 . 1 2 \%}$ \\
White Women & 12 & 554 & 566 & $\mathbf{6 8 . 3 7 \%}$ \\
Men of Color & 4 & 556 & 560 & $\mathbf{3 8 . 5 7 \%}$ \\
White Men & 4 & 538 & 542 & $\mathbf{3 7 . 0 8 \%}$ \\
Total & 36 & 2,180 & 2,216 & \\
Women & 28 & 1,086 & 1,114 & $\mathbf{5 8 . 4 4 \%}$ \\
Men & 8 & 1,094 & 1,102 & $\mathbf{3 7 . 8 4 \%}$ \\
Total & 36 & 1,148 & 2,216 & \\
People of Color & 20 & 1,088 & 1,108 & $\mathbf{4 8 . 6 5 \%}$ \\
White People & 16 & 1,092 & 1,108 & $\mathbf{4 7 . 7 4 \%}$ \\
Total & 36 & 2,180 & 2,216 & \\
\hline
\end{tabular}

For the purposes of this study, shaming involves efforts to taint the public perception of the legislators by exposing something personal, rather than political, that is meant to be hidden or private, taking a personal, rather than political, action that was initially public and recast it in a markedly negative light, or fabricating personal, rather than political, stories intended to be "gotcha" type moments that purport to reveal something about the person's character. “@NancyPelosi still hitting the booze pretty hard @NancyPelosi?! Either that or Botox is rotting your brain!” We hypothesized that attempts to shame would be more common in tweets directed at female legislators than male legislators as well as for legislators of color than white legislators. Both hypotheses were confirmed, as shown in Table 7.3. We found 7.81\% of @mentions directed toward female leaders contained personal shaming, in contrast to $2.81 \%$ of those directed at male leaders (odds ratio: $2.3097,95 \%$ CI: 1.9479 to $2.7386, \mathrm{p}<0.0001$ ). In terms of race, 3.88\% of @mentions directed at white legislators contained attempts to shame, in comparison to $6.14 \%$ of those directed at legislators of color (odds ratio: 1.6194, 95\% CI: 1.0950 to 2.3950, $\mathrm{p}=0.0158$ ). And, as predicted, intersectional abuse is compounding; women of color are by far the most likely to receive @mentions that target them with personal shame (see Figure 7.8). One out of every ten tweets directed at women of color involves shaming, about $40 \%$ more than white women and almost $80 \%$ more than men of color. We are therefore able to confirm the third related hypothesis; attempts to shame are more common in tweets targeting female legislators of color than in those targeting other groups. 


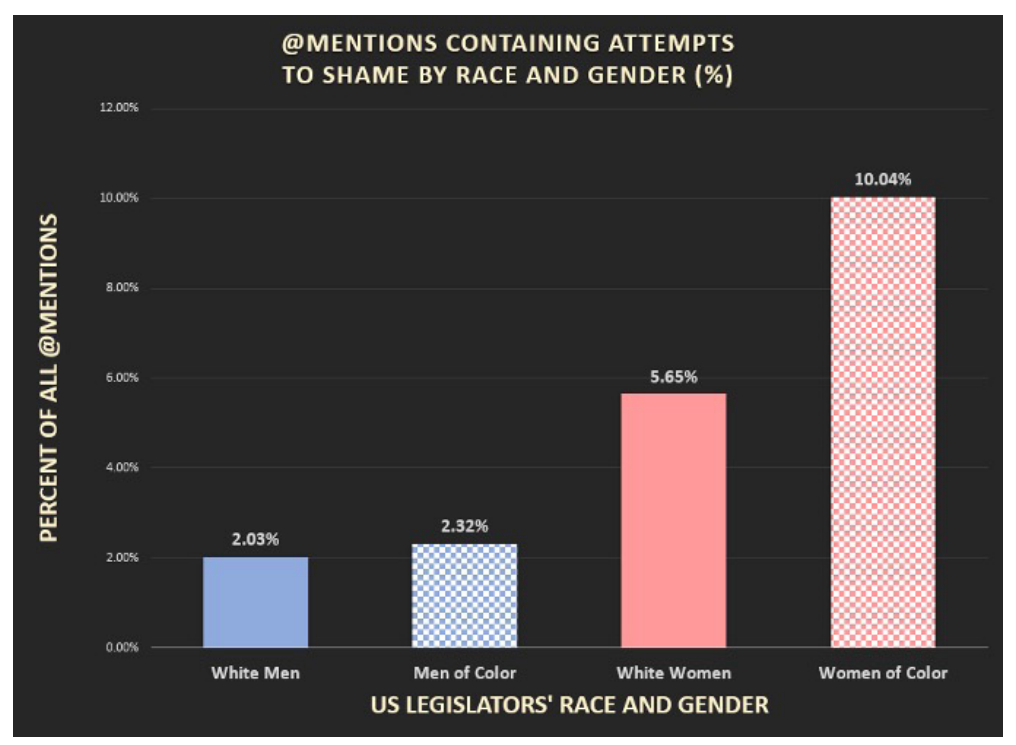

Figure 7.8: @mentions containing attempts to shame.

Table 7.3: @mentions containing attempts to shame.

\begin{tabular}{lllcl}
\hline Legislators Mentioned & \#SHAME & \#NONE & Total & \%SHAME \\
\hline Women of Color & 313 & 235 & 548 & $\mathbf{5 7 . 1 2} \%$ \\
White Women & 387 & 179 & 566 & $\mathbf{6 8 . 3 7 \%}$ \\
Men of Color & 216 & 344 & 560 & $\mathbf{3 8 . 5 7 \%}$ \\
White Men & 201 & 341 & 542 & $\mathbf{3 7 . 0 8} \%$ \\
Total & 1,117 & 1,099 & 2,216 & \\
Women & 651 & 463 & 1,114 & $\mathbf{5 8 . 4 4 \%}$ \\
Men & 417 & 685 & 1,102 & $\mathbf{3 7 . 8 4 \%}$ \\
Total & 1,068 & 1,148 & 2,216 & \\
People of Color & 529 & 579 & 1,108 & $\mathbf{4 8 . 6 5 \%}$ \\
White People & 539 & 569 & 1,108 & $\mathbf{4 7 . 7 4 \%}$ \\
Total & 1,068 & 1,148 & 2,216 & \\
\hline
\end{tabular}

Often when tweets contain attempts to discredit, intimidate or shame their targets, attackers use identity-based pushback as leverage. The next set of hypotheses were intended to test the prevalence of @mentions containing identity-based content. First, we hypothesized that legislators' racial, ethnic and/or religious identity would be invoked more often for people of color than for whites, and that among people of color, women would receive a higher proportion of this content than men. One such example of invoking racial identity: “@SenatorTimScott Hey Timmy boy..i see you the black lackey at the white house.. did you take @LindseyGrahamSC coffee this 
morning. ? you obviously dont like people of your color..you chose a white man over a black man..Afro-Americans going to drop you good.. your career is over." As seen in Table 7.4, both hypotheses were confirmed; tweets directed at legislators of color are almost three times as likely to include references to their race or perceived race (7.04\%) than those positioned toward white legislators (2.53\%) (odds ratio: 2.9238, 95\% CI: 1.88827 to $4.5405, \mathrm{p}<0.0001)$. Gender compounds the abuse; $10.40 \%$ of the tweets @mentioning women of color include race-based commentary in contrast to 2.14\% of those @mentioning men of color (odds ratio: 2.9796, 95\% CI: 1.7802 to 4.9871, $\mathrm{p}<0.0001)$.

The heavy burden on female legislators of color reappears when we explore @ mentions that include comments about elected officials' gender or gender-identity. These kinds of remarks often use gender as a means to devalue or discredit the legislators or their contributions (e.g. “@NancyPelosi Pelousy you're just a commie hag,” “@NancyPelosi they are not Americans, sweetheart” and “@NancyPelosi shut up bitch"). We were able to confirm our hypothesis that gender is invoked more in tweets directed toward female legislators than male legislators; Table 7.5 shows that $7.99 \%$ of tweets @mentioning female leaders reference or comment on their gender, in contrast with $2.90 \%$ of the tweets directed at male leaders (odds ratio: $2.9034,95 \%$ CI: 1.9211 to $4.3879, \mathrm{p}<0.0001$ ). Once again, gender-talk is disproportionately directed at female legislators of color; tweets including this kind of commentary are 1.66 times more likely to target female legislators of color than white female legislators (odds ratio: $1.6584,96 \% \mathrm{CI}: 1.0653$ to $2.5818, \mathrm{p}=0.0251)$.

Table 7.4: Percent of @mentions invoking race (of legislator).

\begin{tabular}{lllll}
\hline Legislators Mentioned & \#RACE & \#NONE & Total & \%RACE \\
\hline People of Color & 78 & 1,029 & 1,108 & $\mathbf{7 . 0 4 \%}$ \\
White People & 28 & 1,080 & 1,108 & $\mathbf{2 . 5 3 \%}$ \\
Total & 106 & 2,109 & 2,216 & \\
Legislators Mentioned & \#RACE & \#NONE & Total & \%RACE \\
Women of Color & 57 & 491 & 548 & $\mathbf{1 0 . 4 0 \%}$ \\
Men of Color & 21 & 539 & 560 & $\mathbf{2 . 1 4 \%}$ \\
Total & 78 & 1,030 & 1,108 & \\
\hline
\end{tabular}


Table 7.5: Percent of @mentions invoking gender (of legislator).

\begin{tabular}{lllll}
\hline Legislators Mentioned & \#GENDER & \#NONE & Total & \%GENDER \\
\hline Women & 89 & 1,025 & 1,114 & $\mathbf{7 . 9 9 \%}$ \\
Men & 32 & 1,070 & 1,102 & $\mathbf{2 . 9 0 \%}$ \\
Total & 121 & 2,095 & 2,216 & \\
Legislators Mentioned & \#GENDER & \#NONE & Total & \%GENDER \\
Women of Color & 54 & 494 & 548 & $\mathbf{9 . 8 5 \%}$ \\
White Women & 35 & 531 & 566 & $\mathbf{5 . 1 2 \%}$ \\
Total & 89 & 1,025 & 1,114 & \\
\hline
\end{tabular}

Our final hypotheses involved direct and indirect comments about elected officials' physical appearance, bodies and/or sexual behavior. For example, one such tweet reads, “@RepMaxineWaters @realDonaldTrump I swear I think James Brown faked his own death and returned in drag as Maxine Waters." We predicted that tweets directed at female legislators would more often include body-based commentary than those directed at their male counterparts. This was confirmed: 4.04\% of @mentions directed at women included such comments, while only $2.18 \%$ of at mentions directed at men did so (odds ratio: $1.9808,95 \%$ CI: 1.1439 to $3.1255, \mathrm{p}=0.0130$ ), as visible in Table 7.6. We can also confirm our hypothesis that body-based comments are more common for female legislators of color than for white women (odds ratio: 2.0334, 95\% CI: 1.0293 to $4.0168, \mathrm{p}=0.0410)$.

Table 7.6: Percent of @mentions containing body commentary.

\begin{tabular}{lllll}
\hline Legislators Mentioned & \#GENDER & \#NONE & Total & \%BODY \\
\hline Women & 45 & 1,069 & 1,114 & $\mathbf{4 . 0 4 \%}$ \\
Men & 24 & 1,078 & 1,102 & $\mathbf{2 . 1 8 \%}$ \\
Total & 69 & 2,147 & 2,216 & \\
Legislators Mentioned & \#GENDER & \#NONE & Total & \%BODY \\
Women of Color & 25 & 523 & 548 & $\mathbf{4 . 5 6 \%}$ \\
White Women & 13 & 553 & 566 & $\mathbf{2 . 3 0 \%}$ \\
Total & 38 & 1,076 & 1,114 & \\
\hline
\end{tabular}


Table 7.7: Summary of hypothesis test results.

\begin{tabular}{|c|c|c|}
\hline$\#$ & Hypothesis & Confirmed? \\
\hline $\mathrm{H} 1 \mathrm{a}$ & $\begin{array}{l}\text { Attempts to discredit will be more common in tweets targeting female } \\
\text { legislators than in those targeting men. }\end{array}$ & YES \\
\hline $\mathrm{H} 1 \mathrm{~b}$ & $\begin{array}{l}\text { Attempts to discredit will be more common in tweets targeting legislators } \\
\text { of color than in those targeting white legislators. }\end{array}$ & NO \\
\hline $\mathrm{H} 1 \mathrm{C}$ & $\begin{array}{l}\text { Attempts to discredit will be more common in tweets targeting female } \\
\text { legislators of color than in those targeting other groups. }\end{array}$ & NO \\
\hline $\mathrm{H} 2 \mathrm{a}$ & $\begin{array}{l}\text { Attempts to intimidate will be more common in tweets targeting female } \\
\text { legislators than in those targeting men. }\end{array}$ & YES \\
\hline $\mathrm{H} 2 \mathrm{~b}$ & $\begin{array}{l}\text { Attempts to intimidate will be more common in tweets targeting legislators } \\
\text { of color than in those targeting white legislators. }\end{array}$ & NO \\
\hline $\mathrm{H} 2 \mathrm{C}$ & $\begin{array}{l}\text { Attempts to intimidate will be more common in tweets targeting female } \\
\text { legislators of color than in those targeting other groups. }\end{array}$ & YES \\
\hline $\mathrm{H} 3 \mathrm{a}$ & $\begin{array}{l}\text { Attempts to shame will be more common in tweets targeting female } \\
\text { legislators than in those targeting men. }\end{array}$ & YES \\
\hline $\mathrm{H} 3 \mathrm{~b}$ & $\begin{array}{l}\text { Attempts to shame will be more common in tweets targeting legislators of } \\
\text { color than in those targeting white legislators. }\end{array}$ & YES \\
\hline $\mathrm{H} 3 \mathrm{C}$ & $\begin{array}{l}\text { Attempts to shame will be more common in tweets targeting female } \\
\text { legislators of color than in those targeting other groups. }\end{array}$ & YES \\
\hline $\mathrm{H} 4 \mathrm{a}$ & $\begin{array}{l}\text { Race (legislator's) will be invoked more in tweets directed toward } \\
\text { legislators of color than in those directed toward white legislators. }\end{array}$ & YES \\
\hline $\mathrm{H} 4 \mathrm{~b}$ & $\begin{array}{l}\text { Race (legislator's) will be invoked more in tweets directed toward female } \\
\text { legislators of color than in those directed toward men of color. }\end{array}$ & YES \\
\hline $\mathrm{H} 5 \mathrm{a}$ & $\begin{array}{l}\text { Gender (legislator's) will be invoked more in tweets directed toward female } \\
\text { legislators than in those directed toward male legislators. }\end{array}$ & YES \\
\hline $\mathrm{H} 5 \mathrm{~b}$ & $\begin{array}{l}\text { Gender (legislator's) will be invoked more in tweets directed toward female } \\
\text { legislators of color than in those directed toward white women. }\end{array}$ & YES \\
\hline H6a & $\begin{array}{l}\text { References to physical appearance, sexual situations, and the body will be } \\
\text { more common in tweets directed toward female legislators than in those } \\
\text { directed toward male legislators. }\end{array}$ & YES \\
\hline $\mathrm{H} 6 \mathrm{~b}$ & $\begin{array}{l}\text { References to physical appearance, sexual situations, and the body will be } \\
\text { more common in tweets directed toward female legislators of color than in } \\
\text { those directed toward white women. }\end{array}$ & YES \\
\hline
\end{tabular}




\subsection{Discussion and Conclusions}

As visible in Table 7.7, 12 of the 15 hypotheses were confirmed, revealing that in the case of US legislators, identity plays a central role in determining who receives negative pushback on social media as well as the ways they are attacked. In other words, people from historically underrepresented groups - particularly women of color - deal with more shaming, discrediting and intimidation, and they also manage a barrage of messages suggesting that they have little of value to contribute because of their gender and race. Attackers draw on racial and gender stereotypes as a way to invalidate the ideas and efforts of people from these underrepresented groups. Attackers are particularly aggressive toward women of color, who receive gendered abuse, racialized abuse and abuse that is intersectional in nature.

While this research documents some of the uneven terrain navigated by US legislators, we suspect the differences are of a greater magnitude than we have been able to capture. Future research would be well served to examine variation in tone and intensity of the messages directed toward political figures from different groups. In looking at the tweets, it is not uncommon to find that even when body-based commentary, for example, is present for white male legislators, it is relatively mild. Mitch McConnell, for example, is often called "turtle," a long-running reference to Jon Stewart saying that McConnell looked like a turtle on The Daily Show. While this is rude and may be hurtful, it feels substantively different from a tweet @mentioning Tammy Duckworth that says, "Bitch please go fuck yourself with a cactus." We attempted summary measures for overall tone, but in examining the interrater evaluations, determined that they were not adequately reliable and were forced to discard them. Future research should work on capturing these critically important distinctions.

Much of this story is bleak, indeed, even white male legislators are unlikely to find Twitter a fully-comfortable environment - almost $40 \%$ of the tweets directed at them include attempts to discredit them. But we were looking for nastiness and did not code for prosocial interaction or substantive political engagement. Had we done so, we might have been able to capture the tweets we read that addressed policy preferences, raised questions and revealed that amid tweets telling Maxine Waters that she is, "a loud mouth neger liberal pile of shit," or telling her to "TAKE OFF THAT SKANKY WIG," there are also tweets that point legislators to attend to issues they feel deserve attention, some that ask questions about how representatives' stated goals would be accomplished, those that work through stories in the news, and those rife with gratitude and celebration. There is value here, at least for some.

These unsettling attempts to limit the political voice and visibility of those from historically underrepresented groups remind us that winning an election does not mean the victors have overcome discrimination. Indeed, the near mandatory presence in digital town halls may place elected officials into closer contact with misogyny/misogynoir and racism than they have had to deal with in the past. This abuse has a variety of personal and political costs for those targeted for attack, but it 
also has social costs: if we lose qualified candidates or hear from people of color and white women less often or more guardedly as a result of this abuse, our digital public spaces contain a narrower range of perspectives. The macro and micro implications

of this hostile work environment will need to be explored more fully, as leaving Twitter, YouTube and Facebook are not practical options in a political context where the populace increasingly gets information via social media platforms and evidence mounts that a robust social media presence helps candidates win elections.

\section{References}

Adams, C. (2018). They Go for Gender First. Journalism Practice, 12(7), 850-69. doi:10.1080/1751278 6.2017.1350115.

Adams, S. J., Hazelwood, T. E., Pitre, N. L., Bedard, T. E., \& Landry, S. D. (2009). Harassment of Members of Parliament and the Legislative Assemblies in Canada by Individuals Believed to Be Mentally Disordered. Journal of Forensic Psychiatry \& Psychology, 20(6), 801-14. doi:10.1080/14789940903174063.

Astor, M. (2018). For Female Candidates, Harassment and Threats Come Every Day. The New York Times, August 24, 2018. Retrieved August, 25, 2018 from https://www.nytimes. com/2018/08/24/us/politics/women-harassment-elections.html.

Bailey, M. (2018). On Misogynoir: Citation, Erasure, and Plagiarism, Feminist Media Studies, 18(4), 762-768. doi:10.1080/14680777.2018.1447395.

Bennett, G. C. (1979). The Heckler and the Heckled in the Presidential Campaign of 1968. Communication Quarterly, 27(2), 28-37. doi:10.1080/01463377909369330.

Bimber, B. (2014). Digital Media in the Obama Campaigns of 2008 and 2012: Adaptation to the Personalized Political Communication Environment. Journal of Information Technology \& Politics, 11(2), 130-150. doi:10.1080/19331681.2014.895691.

Chen, G. M., Pain, P., Chen, V. Y., Mekelburg, M, Springer, N., \& Troger, F. (2018). 'You Really Have to Have a Thick Skin': A Cross-cultural Perspective on How Online Harassment Influences Female Journalists. Journalism, 21(7), 877-895. doi:10.1177/1464884918768500.

Citron, D. K. (2014). Hate Crimes in Cyberspace. Cambridge, MA: Harvard University Press.

Dalton, E. (2017). Sexual Harassment of Women Politicians in Japan. Journal of Gender-Based Violence, 1(2), 205-219. doi:10.1332/239868017x15099566627749.

Daniels, J. (2009). Cyber Racism: White Supremacy Online and the New Attack on Civil Rights. Lanham: Rowman \& Littlefield.

David, G., Munro, M., \& Scott, B. (1996). How to make trouble and influence people: Australasian pranks, hoaxes and political mischief making. Sydney: Political Hooligan Publications.

Dietz, P. E., Matthews, D. B., Martell, D. A., Stewart, T. M., Hrouda, D. R., \& Warren, J. (1991). Threatening and Otherwise Inappropriate Letters to Members of the United States Congress. Journal of Forensic Sciences, 36(5). doi:10.1520/jfs13165j.

Elliott, F. \& Turner, J. (2017). MP Jess Phillips Forced to Filter Her Tweets after 600 Rape Threats in a Day. News / The Times. August 26, 2017. Retrieved November, 10, 2017 from. https://www. thetimes.co.uk/article/mp-jess-phillips-forced-to-filter-her-tweets-after-600-rape-threats-in-aday-6655nr57m.

Evans, H. K., Cordova, V., \& Sipole, S. (2014). Twitter Style: An Analysis of How House Candidates Used Twitter in Their 2012 Campaigns, PS: Political Science \& Politics, 47(2), 454-62. doi:10.1017/s1049096514000389. 
Ferber, A. L. (2018). ‘Are You Willing to Die for This Work?’ Public Targeted Online Harassment in Higher Education: SWS Presidential Address. Gender \& Society, 32(3), 301-20. doi:10.1177/0891243218766831.

Fox, J. \& Teng, W. Y. (2017). Women's Experiences with General and Sexual Harassment in Online Video Games: Rumination, Organizational Responsiveness, Withdrawal, and Coping Strategies. New Media \& Society, 19(8), 1290-1307.

Gardiner, B. (2018). 'It's a Terrible Way to Go to Work:' What 70 Million Readers' Comments on the Guardian Revealed about Hostility to Women and Minorities Online. Feminist Media Studies, 18(4), 592-608. doi:10.1080/14680777.2018.1447334.

Gibbs, B. G., Shafer, K., \& Miles, A. (2017). Inferential Statistics and the Use of Administrative Data in US Educational Research. International Journal of Research \& Method in Education, 40(2), 214-20. doi:10.1080/1743727x.2015.1113249.

Gibson, R., Römmele, A., \& Williamson, A. (2014). Chasing the Digital Wave: International Perspectives on the Growth of Online Campaigning. Journal of Information Technology \& Politics, 11(2), 123-29. doi:10.1080/19331681.2014.903064.

Gorard, S. (2013). Research Design: Creating Robust Approaches for the Social Sciences. London: SAGE.

Graham, T., Broersma, M., Hazelhoff, K. \& Haar, G. van 't. (2013). Between Broadcasting Political Messages and Interacting with Voters. Information, Communication \& Society, 16(5), 692-716. doi:10.1080/1369118x.2013.785581.

Gray, K. L. (2012). Intersecting Oppressions and Online Communities. Information, Communication \& Society, 15(3), 411-428. doi:10.1080/1369118x.2011.642401.

Hoffmann, C. P. \& Suphan, A. (2016). Stuck with 'electronic Brochures'? How Boundary Management Strategies Shape Politicians' Social Media Use. Information, Communication \& Society, 20(4), 551-569. doi:10.1080/1369118x.2016.1200646.

Hoffmann, J. \& Sheridan, L. (2008). Stalking, Threatening, and Attacking Corporate Figures. In Meloy, J. R., Sheridan, L. \& Hoffmann, J. (Eds.), Stalking, Threatening, and Attacking Public Figures (pp. 123-42). doi:10.1093/med:psych/9780195326383.003.0006.

Ibrahim, Y. (2009). The Art of Shoe-throwing: Shoes as a Symbol of Protest and Popular Imagination. Media, War \& Conflict, 2(2), 213-26. doi:10.1177/1750635209104655.

Jackson, N. \& Lilleker, D. (2011). Microblogging, Constituency Service and Impression Management: UK MPs and the Use of Twitter. The Journal of Legislative Studies, 17(1), 86-105. doi:10.1080/13 572334.2011.545181.

James, D. V., Farnham, F. R., Sukhwal, S., Jones, K., Carlisle, J., \& Henley, S. (2016). Aggressive/ intrusive Behaviours, Harassment and Stalking of Members of the United Kingdom Parliament: A Prevalence Study and Cross-national Comparison. The Journal of Forensic Psychiatry \& Psychology, 27(2), 177-97. doi:10.1080/14789949.2015.1124908.

Jungherr, A. (2015). Twitter Use in Election Campaigns: A Systematic Literature Review. Journal of Information Technology \& Politics, 13(1), 72-91. doi:10.1080/19331681.2015.1132401.

Kenski, K., Filer, C. R., \& Conway-Silva, B. A. (2018). Lying, Liars, and Lies: Incivility in 2016 Presidential Candidate and Campaign Tweets During the Invisible Primary. American Behavioral Scientist, 62(3), 286-99. doi:10.1177/0002764217724840.

Kerr, S. S., Tiefenthäler, A., \& Fineman, N. (2018, August, 24). 'Where’s Your Husband?' What Female Candidates Hear on the Trail. The New York Times. Retrieved August, 25, 2018 from https:// www.nytimes.com/video/us/politics/100000006027375/women-politics-harassment.html.

Krook, M. L. (2017). Violence Against Women in Politics. Journal of Democracy, 28(1), 74-88.

Larsson, A. O. \& Ihlen, Ø. (2015). Birds of a Feather Flock Together? Party Leaders on Twitter during the 2013 Norwegian Elections, European Journal of Communication, 30(6), 666-81. doi:10.1177/0267323115595525. 
Lev-On, A. (2011). Campaigning Online: Use of the Internet by Parties, Candidates and Voters in National and Local Election Campaigns in Israel. Policy \& Internet, 3(1), 107-134. doi:10.2202/1944-2866.1045.

McLoughlin, L. \& Ward, S. (2017). Turds, Traitors and Tossers: The Abuse of UK MPS via Twitter. Conference Paper, European Consortium for Political Research, 25-30 April 2017. Cited with permission of the authors.

Meloy, J. R. (2014). Approaching and Attacking Public Figures: A Contemporary Analysis of Communications and Behavior. Journal of Threat Assessment and Management, 1(4), $243-61$. doi:10.1037/tam0000024.

Nakamura, L. (2002). Cybertypes: Race, Ethnicity, and Identity on the Internet. New York: Routledge.

Parks, G. S. \& Heard, D. C. (2009). Assassinate the Nigger Ape: Obama, Implicit Imagery, and the Dire Consequences of Racist Jokes. SSRN Electronic Journal. doi:10.2139/ssrn.1447572.

Sian, K. (2018). Stupid Paki Loving Bitch: The Politics of Online Islamophobia and Misogyny. In Bhatia, M. Poynting, S., \& Tufail, W. (Eds.), Media, Crime and Racism (pp. 117-138). doi:10.1007/978-3-319-71776-0_7.

Sobieraj, S. (2017). Bitch, Slut, Skank, Cunt: Patterned Resistance to Women's Visibility in Digital Publics. Information, Communication \& Society, 21(11), 1700-714. doi:10.1080/1 369118x.2017.1348535.

Sobieraj, S. (2019). Disinformation, Democracy, and the Social Costs of Identity- Based Attacks Online. Social Science Research Council, MediaWell. https://mediawell.ssrc.org/expertreflections.

Sobieraj, S. (2020). Credible Threat: Attacks Against Women Online and the Future of Democracy. New York: Oxford University Press.

Stambolieva, E. (2017). Methodology: Detecting Online Abuse against Women MPs on Twitter. Amnesty International. Retrieved from https://apo.org.au/sites/default/files/ resource-files/2017-09/apo-nid107651.pdf.

Sweetser, K. D. \& Lariscy, R. W. (2008). Candidates Make Good Friends: An Analysis of Candidates Uses of Facebook. International Journal of Strategic Communication, 2(3), 175-98. doi:10.1080/15531180802178687.

Temkin, B. \& Yanay, N. (1988) 'I Shoot Them with Words’: An Analysis of Political Hate-Letters. British Journal of Political Science, 18(4), 467. doi:10.1017/s0007123400005226.

Veletsianos, G., Houlden, S., Hodson, J., \& Gosse, C. (2018). Women Scholars' Experiences with Online Harassment and Abuse: Self-protection, Resistance, Acceptance, and Self-blame. New Media \& Society, 20(12),4689-4708. doi:10.1177/1461444818781324.

Waisbord, S. \& Amado, A. (2017). Populist Communication by Digital Means: Presidential Twitter in Latin America. Information, Communication \& Society, 20(9), 1330-346. doi:10.1080/1 369118x.2017.1328521. 


\section{Appendix A: Thumbnail Descriptions of Key Variables}

\section{ATTEMPTS TO DISCREDIT}

This variable is intended to measure whether the tweet suggests that the elected official is not qualified, capable, well-informed, trustworthy, or deserving of respect. Attempts to discredit generally work to deflate or undercut a person's status (see codebook for detailed examples).

\section{INTIMIDATION}

This variable is intended to measure whether the tweet contains direct or indirect threats of reputational, political, or physical harm to the elected official, those close to them, or their party. This code was not be used for dispassionate political forecasting (i.e. "this could hurt their chances for reelection"); it was be reserved for attempts to intimidate (see codebook for detailed examples).

\section{PERSONAL SHAMING}

This variable is intended to measure whether the tweet includes efforts to publicly humiliate or contaminate the public perception of the target as a person. Personal shame: 1) exposes something personal that is meant to be hidden or private (or pile on when someone else does so), 2) takes a personal action that was initially public and recast it in a markedly negative light, or 3) fabricates personal stories intended to be "gotcha" type moments that purport to reveal something about the person's character. Note that political shame, such as suggesting someone's political decisions have been shaped by financial interests, were counted as "discredit," not personal shame (see codebook for detailed examples).

\section{RACE/RACIALIZATION}

This variable is intended to measure whether the tweet contains direct or indirect comments about the elected official's perceived racial, ethnic, or religious identity. The variable is - at its heart - intended to capture how often and for whom racial / ethnic / religious identity is invoked. (see codebook for detailed examples). 


\section{GENDER TALK}

This variable is intended to measure whether the tweet contains direct or indirect comments about the elected official's stated or perceived gender identity. The variable is - at its heart - intended to capture how often and for whom gender identity is invoked (see codebook for detailed examples).

\section{BODY-BASED COMMENTARY}

This variable is intended to measure whether the tweet contains direct or indirect comments about the elected official's physical appearance or sexual behavior. (see codebook for detailed examples). 